\title{
Development of Vulnerability through the DRASTIC Method and Geographic Information System (GIS) (Case Groundwater of Berrchid), Morocco
}

\author{
Halima Elfarrak, Mustapha Hakdaoui, Ahmed Fikri \\ Faculté des Sciences Ben M’Sik, Casablanca, Morocco \\ Email: halima_elfarrak@hotmail.com
}

Received November 15, 2013; revised December 15, 2013; accepted December 22, 2013

Copyright (C) 2014 Halima Elfarrak, et al. This is an open access article distributed under the Creative Commons Attribution License, which permits unrestricted use, distribution, and reproduction in any medium, provided the original work is properly cited. In accordance of the Creative Commons Attribution License all Copyrights (C) 2014 are reserved for SCIRP and the owner of the intellectual property Halima Elfarrak, et al. All Copyright (C) 2014 are guarded by law and by SCIRP as a guardian.

\begin{abstract}
The vulnerability map is a fondamental document for the development of territory. It basically allows you to guide the siting of development projects that may have a negative impact on the quality of groundwater resources. The Geographic Information Systems are powerful tools of choice for the development of vulnerability maps of aquifers, they facilitate multicriteria analysis and updated models developed. Given the strategic role of the underground water Berrechid in the economic and social development of the region of Bouregreg-chaouia, development, we proceeded to develop the vulnerability map of this area by exploiting the features offered by the GIS Arc GIS 9.3 extensions Spatial Analysis Tools and Geostatistical Analyst allowed us to calculate the indices of seven parameters of the DRASTIC method, these indices were classified into five categories: Extreme, High, Medium, Low, Very Low. Developed the card can be used as a tool for decision support in planning and helps to preserve the groundwater in the area Berrechid and surrounding areas.
\end{abstract}

\section{KEYWORDS}

\section{Remote Sensing; GIS, DRASTIC; Vulnerabilities; Groundwater; Berrechid}

\section{Introduction}

The groundwater is an important resource exploited for human consumption and for use in agricultural and industrial fields. These waters are often threatened by contamination with a various kind of pollutants: biological, chemical or physical. The Prevention against the groundwater pollution is an important step, which scientists agree more effort, including exploring the vulnerability of groundwater.

Our studies made on the Groundwater of Berrechid This one is located in a plain mainly exploited for agriculture, with a consumption of ever increasing use of chemical fertilizers. Thus, this work was carried out in order to check the validity of the method of standard DRASTIC vulnerability [1]. It takes into account the intrinsic characteristics of the aquifer by exposing his predisposition or vulnerability to pollution-related activity from the soil surface.
The DRASTIC method only takes into account the hydrogeological factors influencing vulnerability.

These physical properties that play a role in the migration and attenuation of contaminants in the soil complex ventilated area aquifer. Seven parameters are considered: the depth of the water, the annual effective aquifer recharge, aquifer lithology, soil type, topography, impact of the vadose zone and hydraulic conductivity the aquifer.

Seven parameters are considered: the depth of the water, the annual effective aquifer recharge, aquifer lithology, soil type, topography, impact of the vadose zone and hydraulic conductivity the aquifer.

\section{Drastic Method}

There is no absolute method for assessing the vulnerability of groundwater groundwater, but several methods for estimating the sensitivity of aquifers to pollution have 
been developed [2] as part of this study.

The DRASTIC method, which belongs to the group of weighted classes, is a system that was developed by [3] as a means to evaluate the intrinsic vertical groundwater vulnerability to pollution by parametric systems, the common principle of these systems is to first select the parameters on which to base the assessment of vulnerability. Each parameter is divided into intervals of signifycant value and is assigned a numerical rating increasing, according to its importance in vulnerability.

In practice, each parameter was divided into intervals of significant values and has been assigned a numerical rating increasing, according to its importance in vulnerability. The acronym DRASTIC stands for the initials of seven factors determining the value of the vulnerability index [4]: the water depth (D), the effective charge (R) materials of the aquifer (A), the type of ground (S), the topography or the slope $(\mathrm{T})$, the impact area vadose zone or aerated (I) and the permeability or hydraulic conductivity of the aquifer (C). Each parameter is assigned a scale comprising intervals where a rating is assigned according to the peculiarity of the environment. Each parameter has been classified into classes associated with scores ranging from 1 to 10 . Table 2 For example, the deeper the water, the greater the odds are low. Each of the seven parameters was then multiplied by a scaling factor (Dp) sets 1 to 5 which increases with the importance of the parameter in the estimation of vulnerability Table 1.

The DRASTIC vulnerability index denoted ID Equation (1) was determined. It describes the degree of vulnerability of each hydrogeological unit. The ID was calculated by summing the products of the weight measured from the corresponding parameters according to Equation (1):

$$
\begin{aligned}
\mathrm{ID}= & \mathrm{Dc} \times \mathrm{Dp}+\mathrm{Rc} \times \mathrm{Rp} \\
& +\mathrm{Ac} \times \mathrm{Ap}+\mathrm{Sc} \times \mathrm{Sp}+\mathrm{Tc} \times \mathrm{Tp} \\
& +\mathrm{Ic} \times \mathrm{Ip}+\mathrm{C} c \times \mathrm{Cp}
\end{aligned}
$$

where D, R, A, S, T, I and C are the seven parameters of the DRASTIC method, Table 1.

" $\mathrm{p}$ " is the weight of Parameter and " $\mathrm{c}$ " the rating associated.

D: Depth to Groundwater

The depth from the ground surface to the water table in unconfined aquifer and to the bottom of the confining layer in confined aquifer.

\section{R: Net Recharge}

The total quantity of water is applied to the ground surface and infiltrates to reach the aquifer.

A: Aquifer Media, Consolidated or unconsolidated rock which serves as an aquifer (such as sand, gravel, and limestone).

\begin{tabular}{|c|c|c|c|}
\hline \multicolumn{2}{|c|}{ Symbole parameter } & \multirow{2}{*}{$\begin{array}{l}\text { properties } \\
\text { When this depth of water is high the } \\
\text { contaminant takes a long time to reach } \\
\text { the water table. }\end{array}$} & \multirow{2}{*}{$\begin{array}{l}\text { weight } \\
5\end{array}$} \\
\hline D & $\begin{array}{l}\text { Depth of } \\
\text { water }\end{array}$ & & \\
\hline $\mathbf{R}$ & Net recharge & $\begin{array}{l}\text { the main vehicle For contaminant } \\
\text { transport. Moreover, this charge is high } \\
\text { the risk of contamination is high. }\end{array}$ & \\
\hline A & $\begin{array}{l}\text { Aquifer } \\
\text { lithology }\end{array}$ & $\begin{array}{l}\text { Characterized by the particle size of } \\
\text { saturated soils. It is involved in trapping } \\
\text { the pollutant that can escape the } \\
\text { absorption capacity of the soil. More } \\
\text { granulometry is finer, trapping the } \\
\text { pollutant is great. }\end{array}$ & 3 \\
\hline$S$ & Soil & $\begin{array}{l}\text { more the soil is rich in clay, the greater } \\
\text { the absorption of heavy metals is } \\
\text { important, and the protection of } \\
\text { groundwater is high. }\end{array}$ & 2 \\
\hline $\mathbf{T}$ & Topography & $\begin{array}{l}\text { More the slope of the land is high, the } \\
\text { greater the runoff is important and } \\
\text { therefore the groundwater } \\
\text { contamination is low. }\end{array}$ & 1 \\
\hline I & $\begin{array}{l}\text { Insaturated } \\
\text { zone }\end{array}$ & $\begin{array}{l}\text { Its impact is determined from the } \\
\text { texture of land that constitute it. The } \\
\text { percolation of the pollutant to the water } \\
\text { table is much larger than the texture is } \\
\text { favorable (gravel, coarse sand...). }\end{array}$ & \\
\hline C & Permeability & $\begin{array}{l}\text { Over this parameter is large, Over the } \\
\text { transfer of the pollutant is fast. }\end{array}$ & 3 \\
\hline
\end{tabular}

S: Soil Media, The uppermost portion of the vadose
Table 1. The weight of DRASTIC parameters.

zone characterized by significant biological activity

T: General Topography or Slope The slope and slope variability of the land surface

I: Vadose Zone, The zone above the water table which is unsaturated or discontinuously saturated

C: Hydraulic Conductivity of the Aquifer:

The ability of the aquifer materials to transmit water

The values of the weight parameters of the DRASTIC method used are those defined by [3]. These values are shown in Table 1.

As the values of the DRASTIC index used, they are provided by [4] and represent the extent of the hydrogeological aquifer vulnerability. This index spans the whole range from 23 to 230 [5].

These values represent the extent of the hydrogeological aquifer vulnerability and are within the range of theoreti cal values according to the classification of Engel et al. (1996) as mentioned in Table 2.

The other classification can set limits intervals calculated indices and match classes of vulnerability to these indices.

\section{Overview of the Study Area}

The Plain of Berrechid, a nearby total area of $1500 \mathrm{~km}^{2}$, is located on south of Casablanca. It takes the form of a large bowl, limited to the south and south east by the 
Table 2. (a) Classes and notes used for Depth of water (D); (b) Classes and notes used for net recharge (R); (c) Classes and notes used for aquifer lithology (A); (d) Classes and notes used for soil (S); (e) Classes and notes used for topography (T); (f) Classes and notes used for insaturated zone (I); (g) Classes and notes used for permeability (C).

(a)

\begin{tabular}{cc}
\hline Class (m) & Note \\
\hline $0-1.5$ & 10 \\
$1.5-4.5$ & 9 \\
$4.5-9$ & 7 \\
$9.0-15.0$ & 5 \\
$15-23$ & 3 \\
$23-30$ & 2 \\
$>30$ & 1 \\
\hline
\end{tabular}

(b)

\begin{tabular}{cc}
\hline Class $(\mathbf{m m})$ & Note \\
\hline $0-50$ & 1 \\
$50-100$ & 3 \\
$100-175$ & 6 \\
$175-225$ & 8 \\
$>225$ & 9 \\
\hline
\end{tabular}

(c)

\begin{tabular}{ccc}
\hline Class & Note & typical Note \\
\hline Massive shale & $1-3$ & 2 \\
Metamorphic & $2-5$ & 3 \\
$\begin{array}{c}\text { Metamorphic } \\
\text { Altered-Sandstone }\end{array}$ & $3-5$ & 6 \\
Limestone massive & $4-9$ & 8 \\
sandstone & $4-9$ & 6 \\
Sand and gravel & $4-9$ & 8 \\
Basalt & $2-10$ & 9 \\
limestone Karst & $9-10$ & 10 \\
\hline
\end{tabular}

(d)

\begin{tabular}{cc}
\hline Class & Note \\
\hline Thin or absent & 10 \\
gravel & 10 \\
sands & 9 \\
sandy loam & 6 \\
silts & 4 \\
silty loam & 3 \\
clays & 1 \\
\hline
\end{tabular}

(e)

\begin{tabular}{ccc}
\hline Range of slope (in degrees) & Note \\
\hline $0-2$ & 10 \\
$2-6$ & 9 \\
$6-12$ & 3 \\
$12-18$ & & 1 \\
$>18$ & & \\
& (f) & \\
\hline Note & Note typique \\
\hline Nature lithological & $2-6$ & 3 \\
Silt and clay & $2-6$ & 3 \\
Shale & $2-5$ & 3 \\
limestone & $2-7$ & 6 \\
sandstone & $4-8$ & 6 \\
Sand and gravel with silt and clay pass & $4-8$ & 8 \\
Sand and gravel & $2-10$ & 9 \\
basalt & $8-10$ & 10 \\
limestone Karst & & \\
\hline
\end{tabular}

(g)

\begin{tabular}{cc}
\hline Range of permeability $(\mathbf{m} / \mathbf{s})$ & Note \\
\hline $1.5 * 10^{-7}-5 * 10^{-5}$ & 1 \\
$5 * 10^{-5}-15 * 10^{-5}$ & 2 \\
$15^{*} 10^{-5}-33^{*} 10^{-5}$ & 4 \\
$33^{*} 10^{-5}-5 * 10^{-4}$ & 6 \\
$5 * 10^{-4}-9.5 * 10^{-4}$ & 8 \\
$>9.5 * 10^{-4}$ & 10 \\
\hline
\end{tabular}

board Settat, east and north east by the Wadi Mellah, West and northwest by Primary outcrops and the North by Coast chaouia [6].

The basement of the plain Berrechid contains the largest water recognized across the zone of action of ABHBC. Soil fertility in the entire plain, easy access to the water and its proximity near the largest city in Morocco, and the relative mild climate of the region are all factors that are cause accelerated groundwater exploitation of the plain.

On the hydrogeological plan, the Berrechid groundwater flows in primary training, Tertiary and Plio-Quaternary (Figure 1). However, and in light of the results of previous studies, the Pliocene terrain remains by far the main asquifer.

The limits of Berrechid groundwater are as follows:

- In the South and South-east: the groundwater limited by the salver of Settat which plunges under the plain 
through flexures and faults and forming the Eocene substratum;

- In the north-east: the valley of Oued El Mellah (Figure 1) notched in the red clay of Permo-Trias (Figure 2), marks clearly the limit of the hydrogeological grounwater;

- In the north: the plain of chaouia low (Figure 1) which is the natural extension of Berrechid plain make a limit of groundwater of Berrechid;

- To the west and north-west, the primary outcrops (Figure 1) form a free boundary of the groundwater [7].

\section{Materiel and Method}

The geographic information systems are all hardware, software, methods and users can acquire, store, analyze, and display geographic intéroger information or we exclude the architecture and functionality of a GIS (System Information Geographic) architecture GIS: methods, materials, software, data and users

GIS are designed to collect diverse spatial data to represent spatially variable phenomena by applying a series of overlay analysis of data layers that are in spatial register [8].

In this study of vulnerability in the plain of Berrechid we used:

A Landsat satellite image taken: 2012 (Enhanced Thematic map sensor ETM+).

A DEM SRTM (Shuttle Radar Thematic Mapper). The MNT was georeferenced in a Geographic Information System (GIS) and the UTM WGS 84 (World Geodetic System 1984).

Ancillary data include topographic map and geological map of the plain of Berrechid This approach is outlined in Figure 2.

For each DRASTIC parameter is assigned a score on a whole (most important) scale ranging from 1 (least important) to 10 . For a given parameter, a low score means that the water in question is not vulnerable to pollution and vice versa.

The scale is full (discrete), so it is natural that the values obtained for each of the parameters are grouped into classes, each with a unique number.

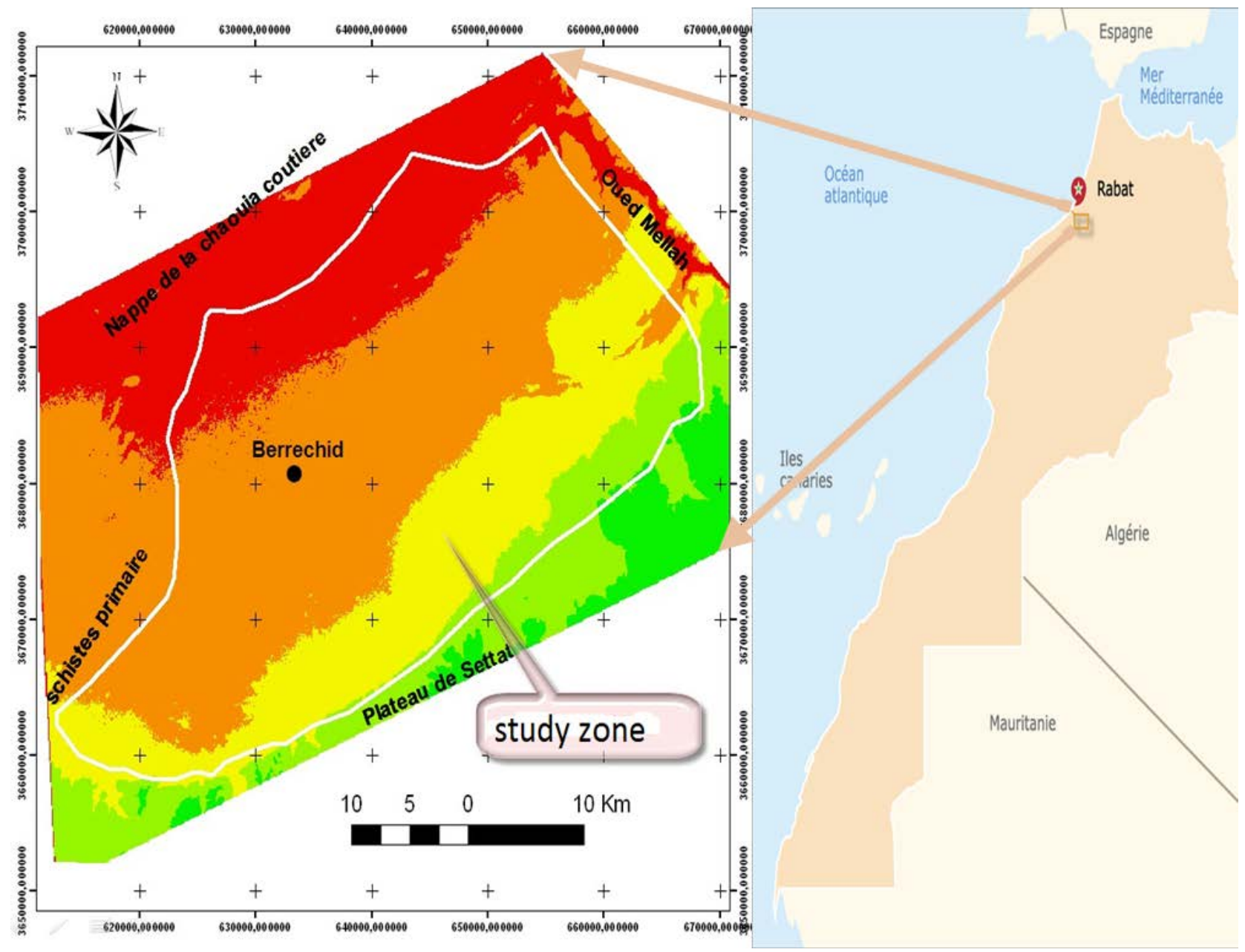

Figure 1. Geological presentation of the Berrechid groundwater [6]. 
When the DRASTIC score is displayed via a GIS, the spatial relationship between land management practices and groundwater vulnerability is illustrated. All DRASTIC data elements are incorporated, manipulated, interpreted, and displayed using a GIS. The resulting output is a spatially oriented dataset showing the hydrogeologic setting and areas of groundwater vulnerability to contamination. The particular GIS software tool used in this analysis is the ArcView software package.

The following tables show typical scores for each of the seven parameters:

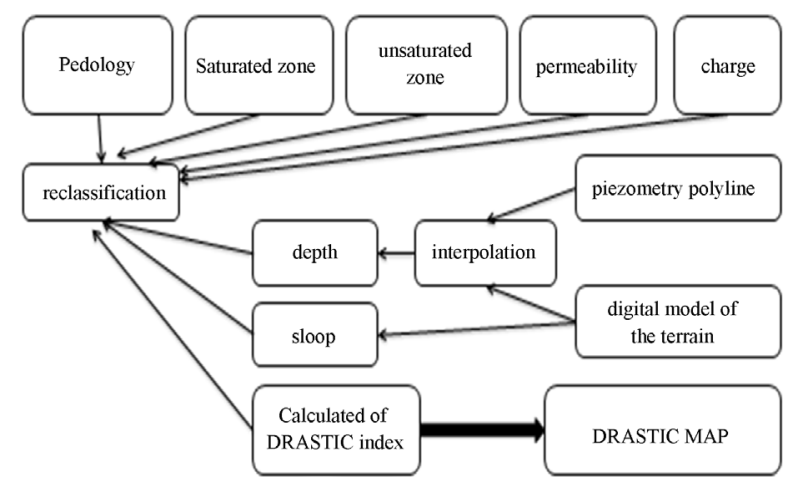

Figure 2. Methodological flowchart for integration into GIS.

\section{Results}

After defining the different classes Figures 10-16 for each of parameters Figures 3-9, it is then possible to calculate the DRASTIC index Figure 17.

The index, I, is the sum of the scores obtained for each DRASTIC seven parameters, weighted Table 1 by the respective coefficients of these. The formula is as follows:

$$
\begin{aligned}
\mathrm{I}= & \mathrm{rDND}+\mathrm{rRNR}+\mathrm{rANA}+\mathrm{rSNS} \\
& +\mathrm{rTNT}+\mathrm{rINI}+\mathrm{rCNC}
\end{aligned}
$$

where:

The rI are the weight of DRASTIC parameters Table 1.

NI are notes or class of DRASTIC parameters Figures 10-16.

I is the vulnerability of Berrechid aquifer Figure 17.

\section{Validation Vulnerability Maps}

Any map developed vulnerability is tested and validated by measurement and analysis of chemical data of groundwater. Indeed, several authors [9-14].

Tested the validity of vulnerability assessment methods to pollution based on chemical data of groundwater.

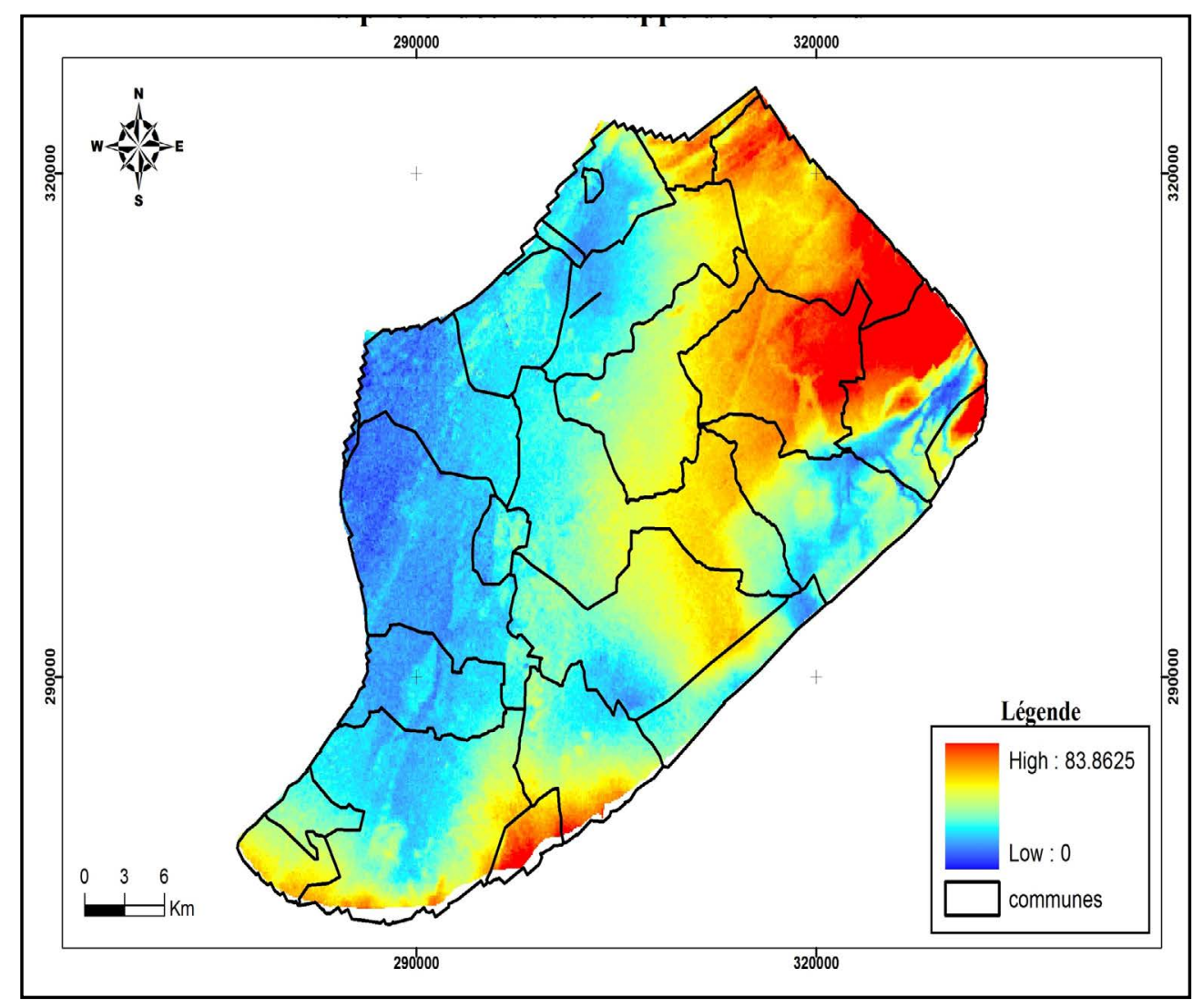

Figure 3. Map of ground water depth (D). 


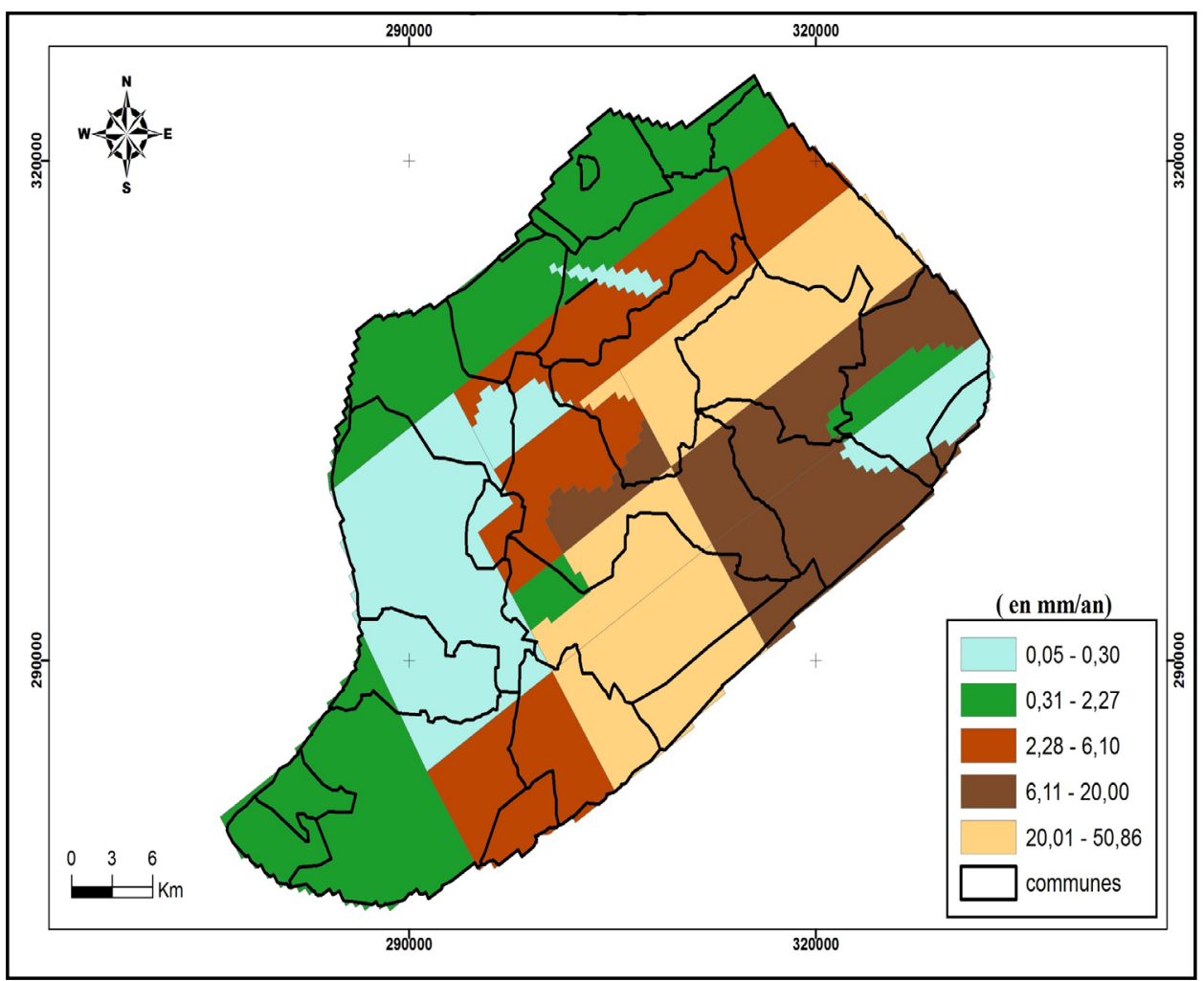

Figure 4. Map of ground water net recharge (R).

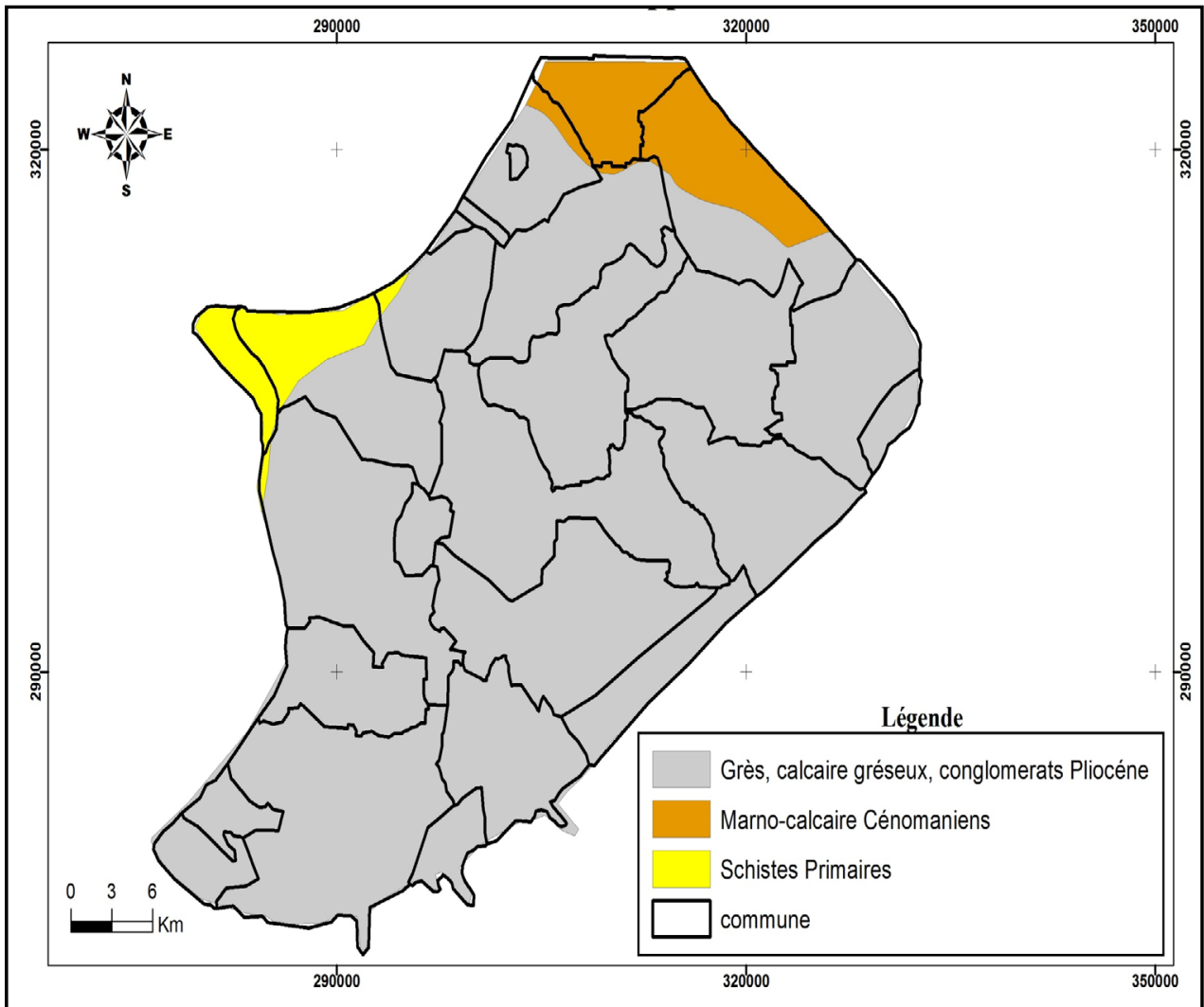

Figure 5. Map of aquifer lithology (A). 


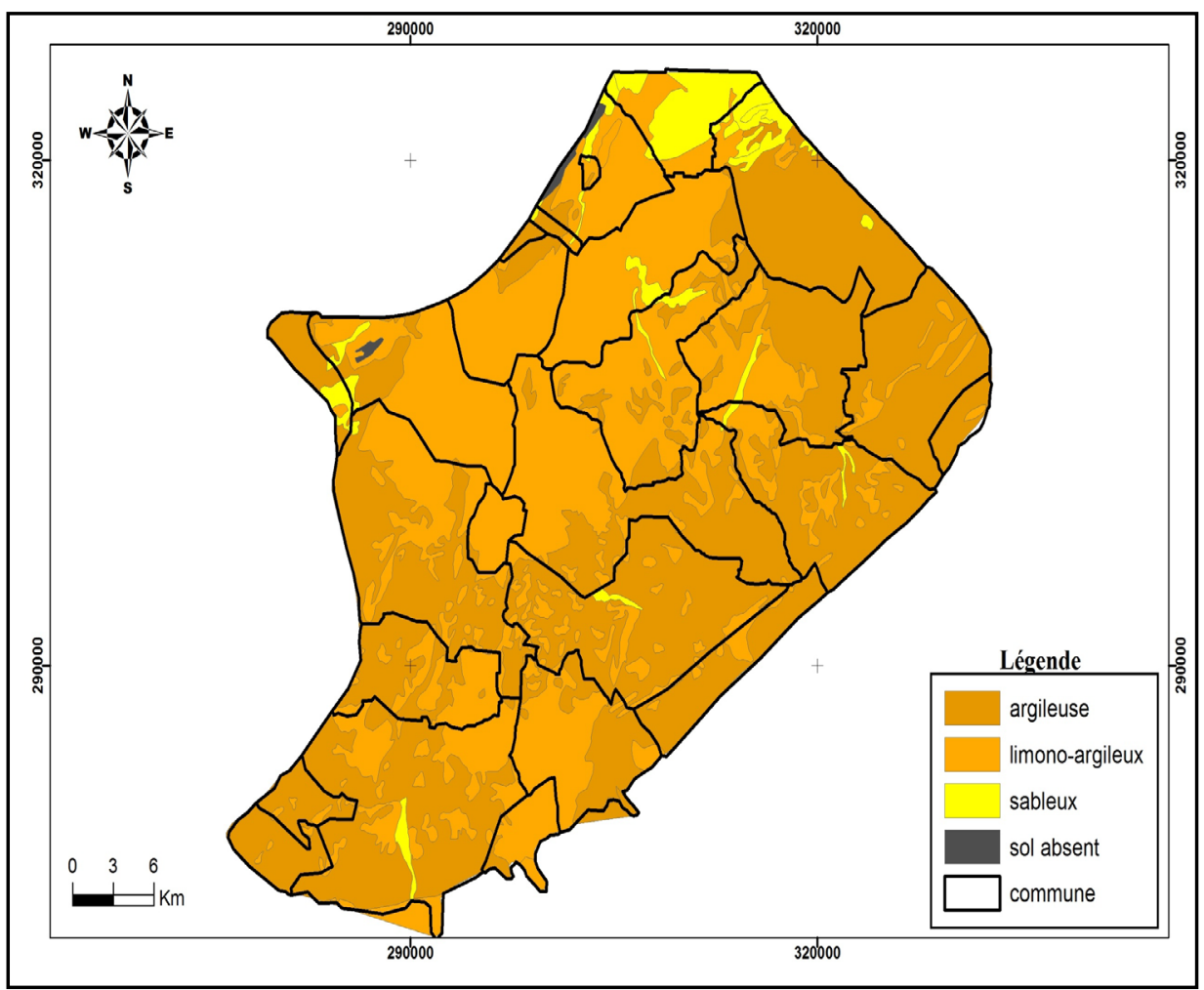

Figure 6. Map of ground water pedology (S).

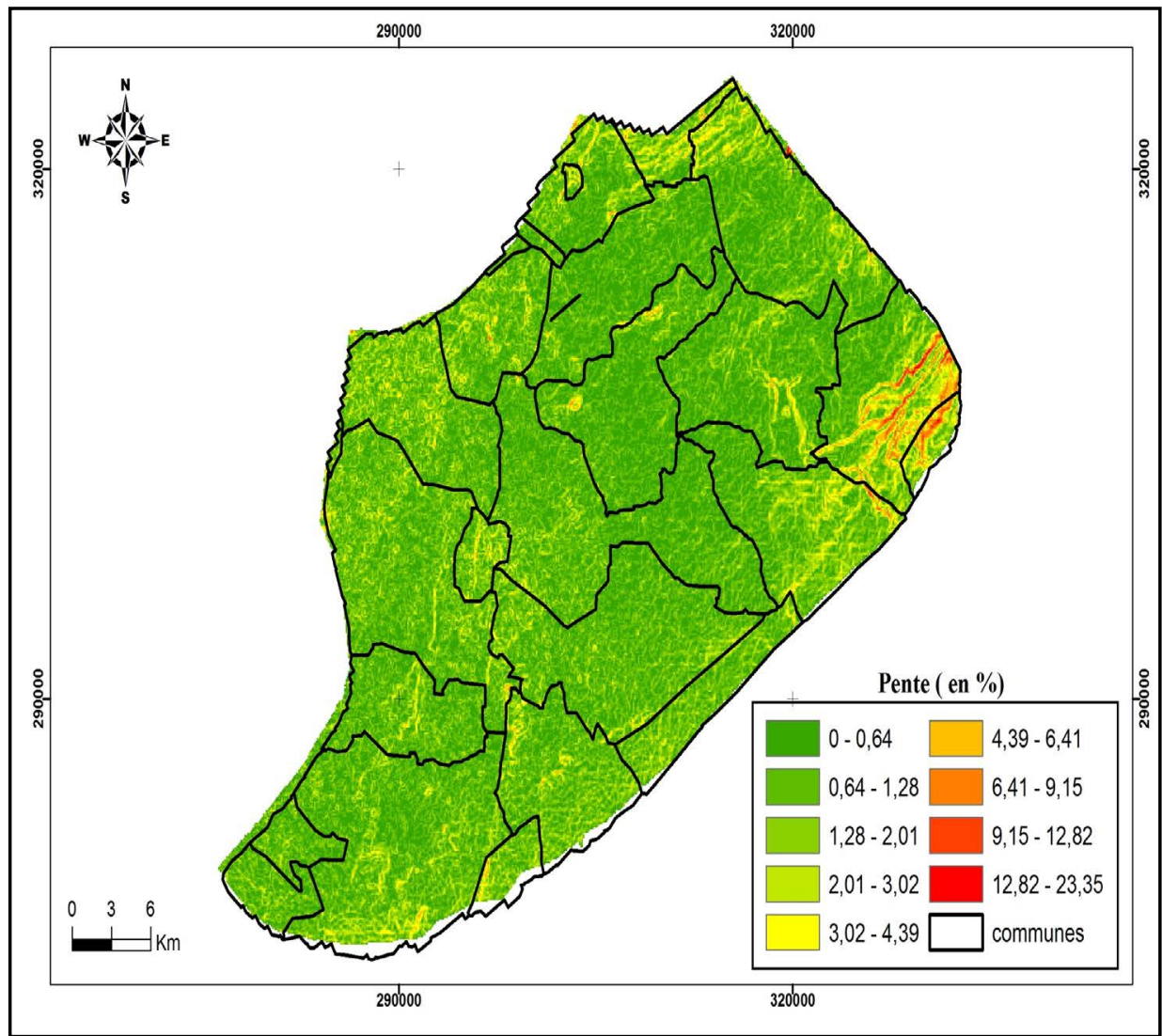

Figure 7. Map of aquifer topography (T). 


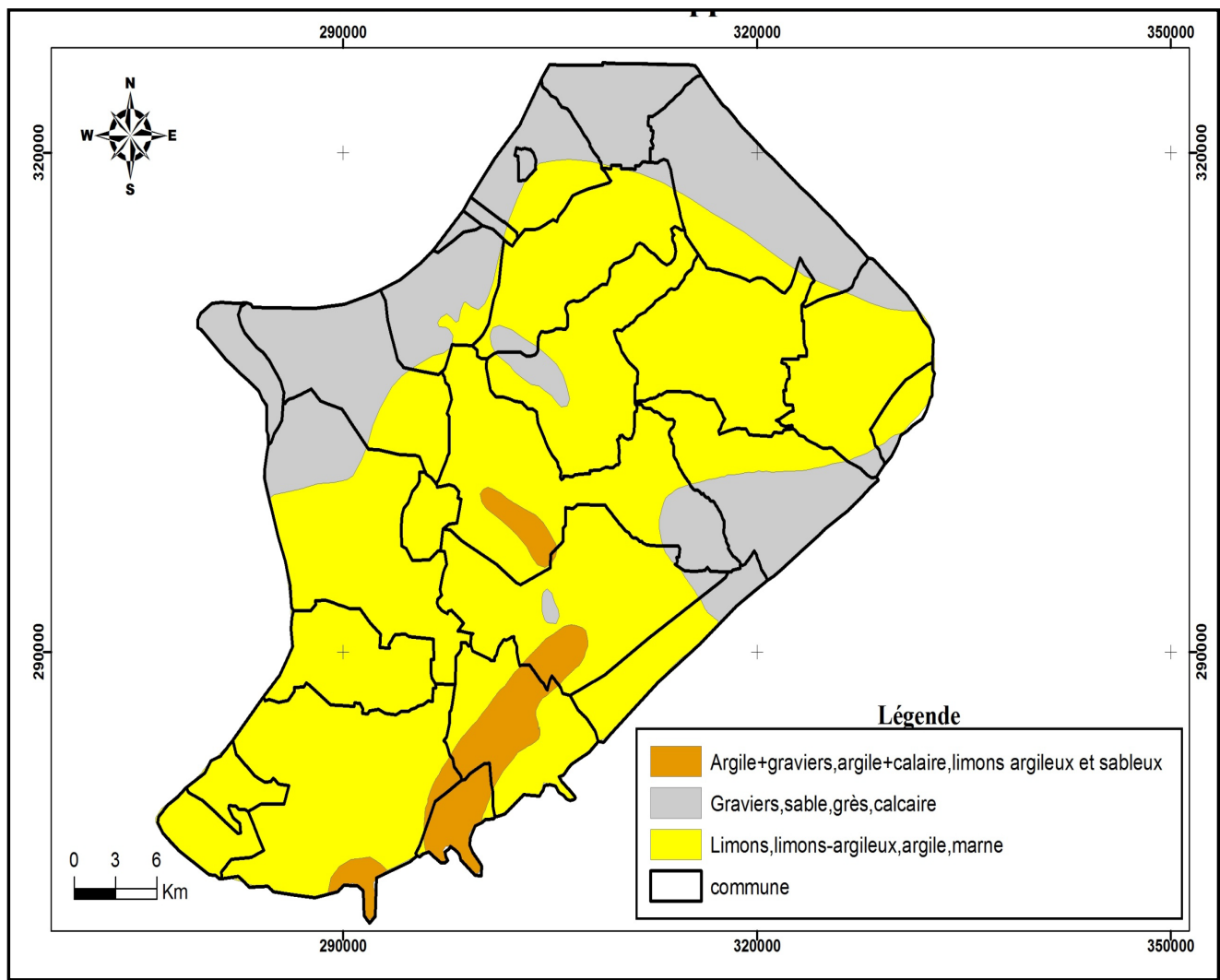

Figure 8. Map of ground water insaturated zone (I).

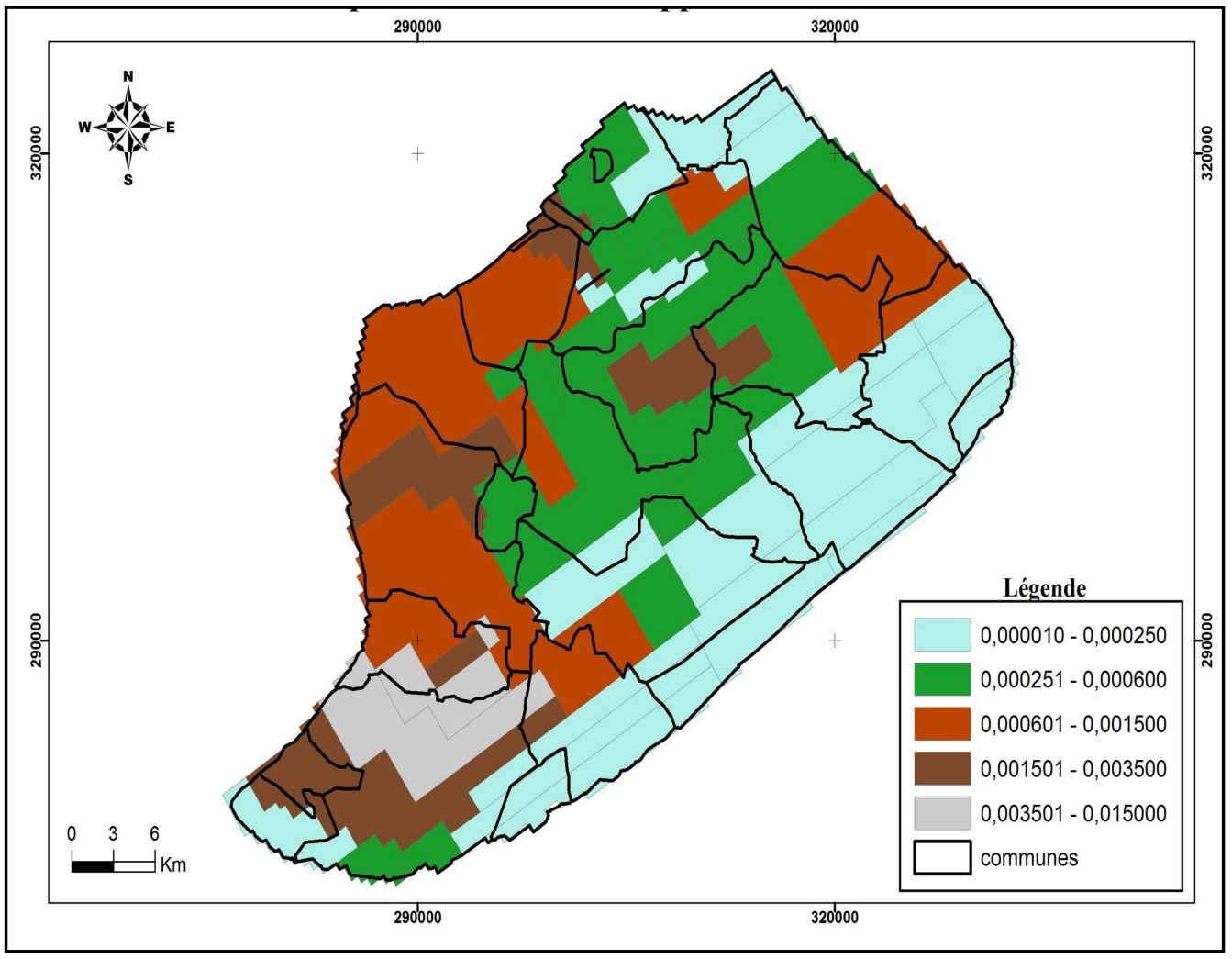

Figure 9. Map of ground water permeability (C). 


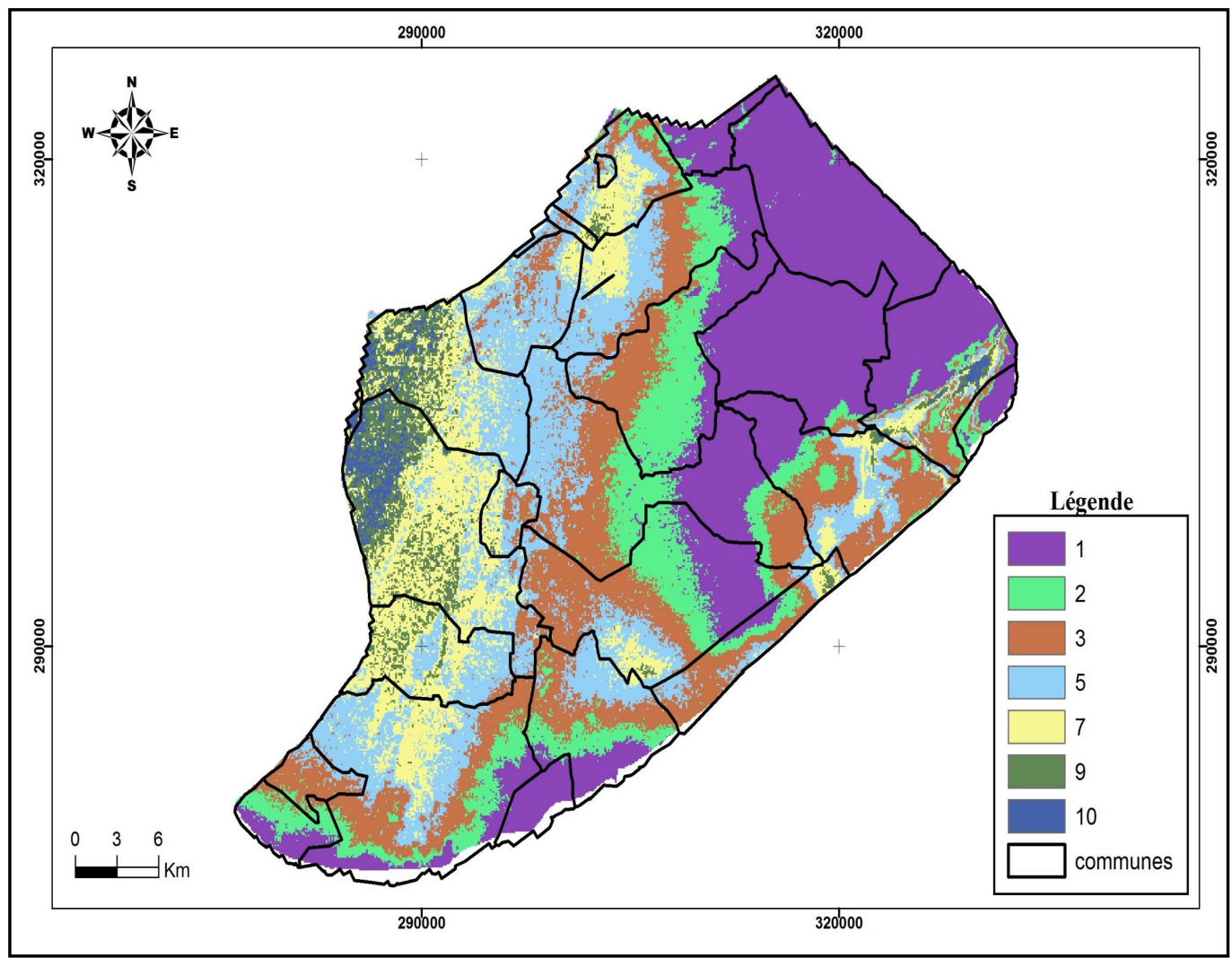

Figure 10. Map of ground water depth after reclass.

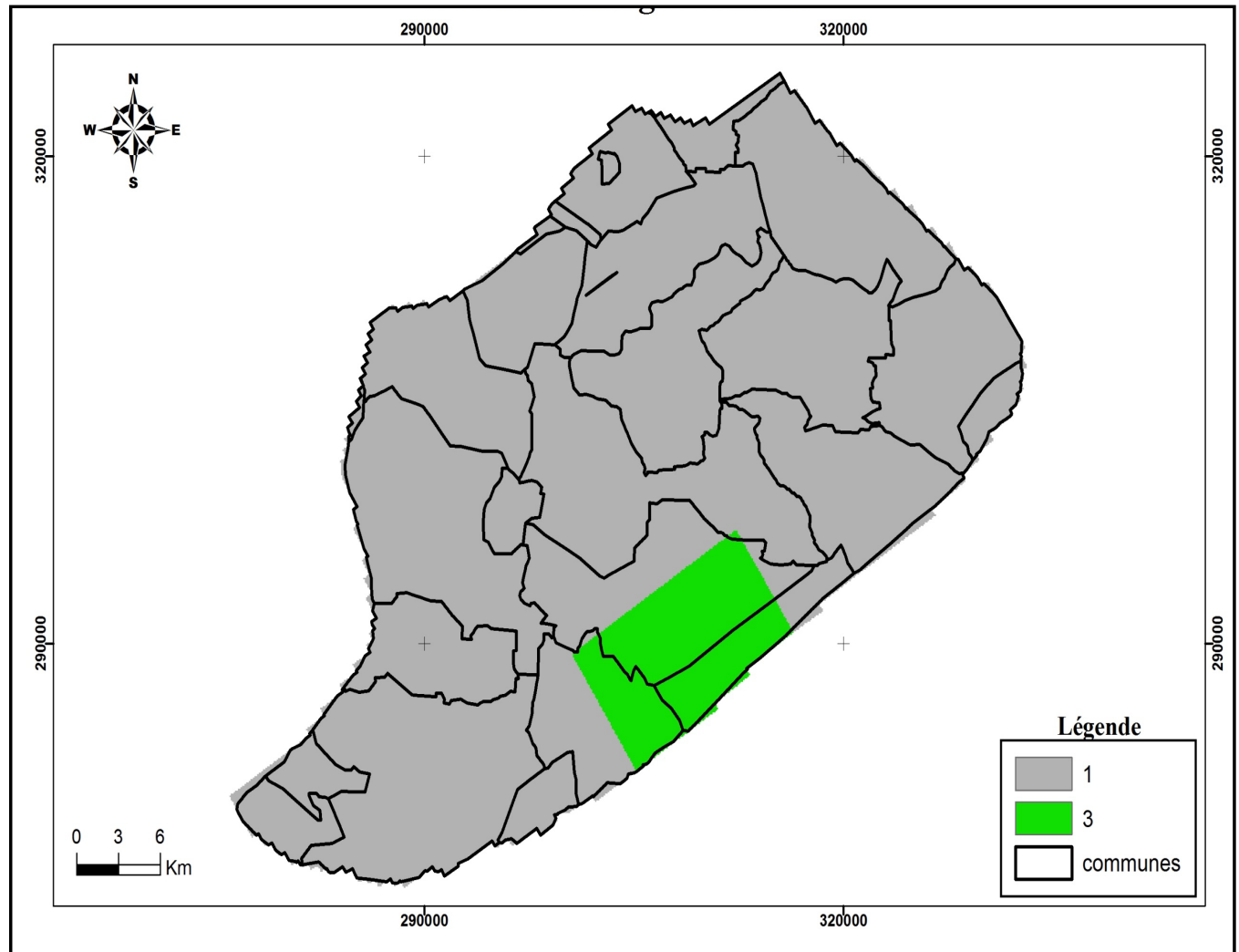

Figure 11. Map of ground water net recharge after reclass. 


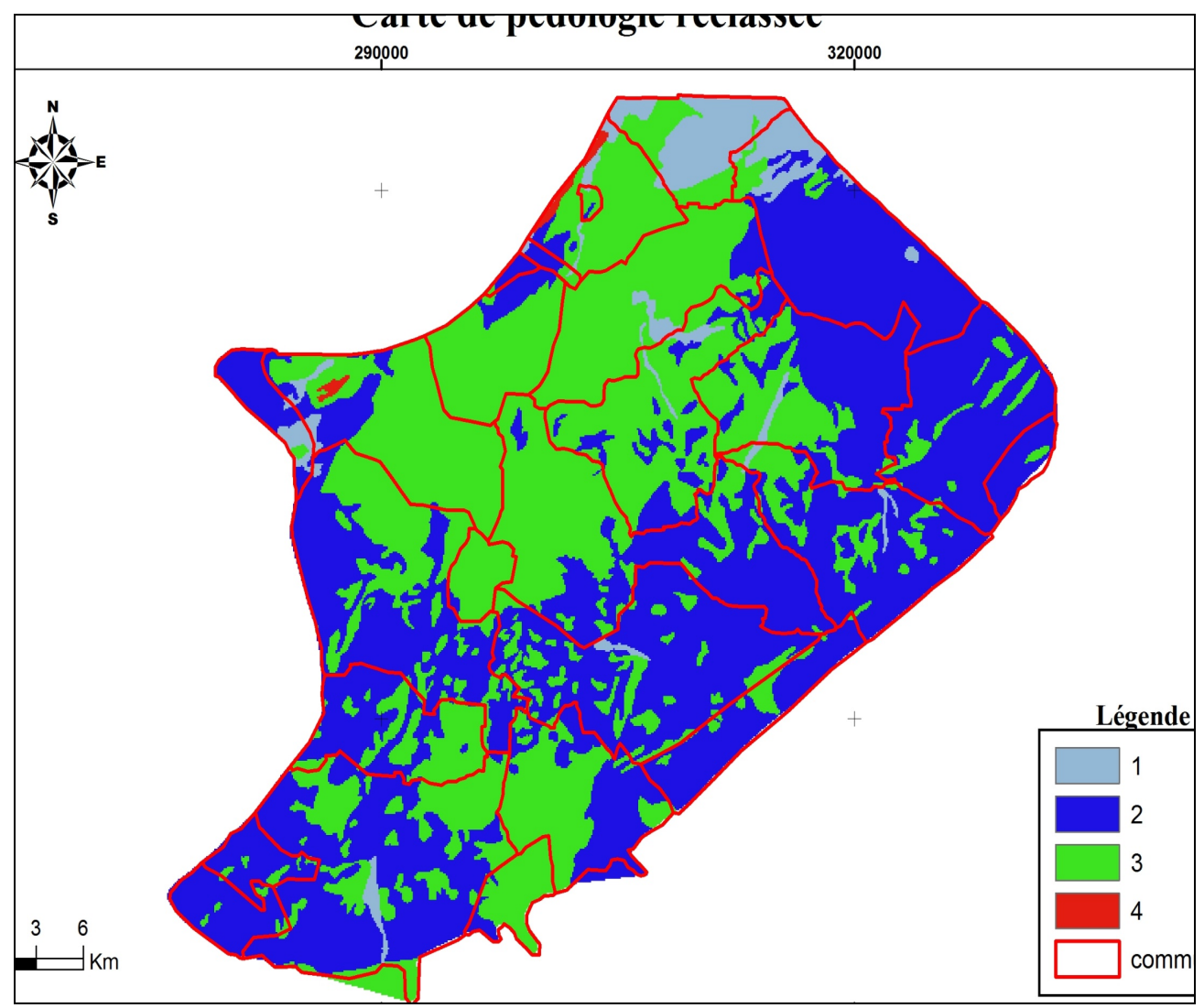

Figure 12. Map of ground water insaturated zone after reclass.

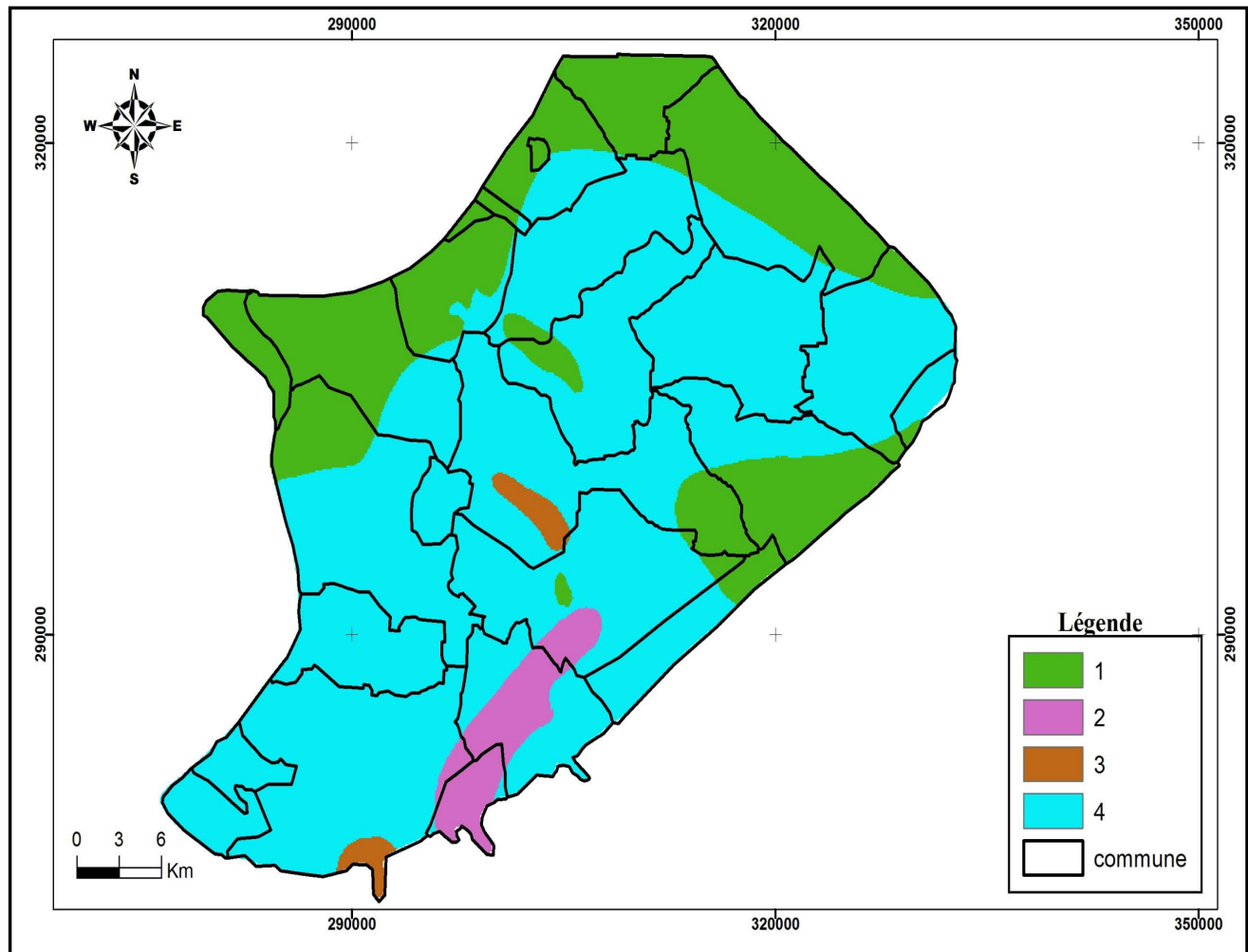

Figure 13. Map of ground water pedology after reclass. 


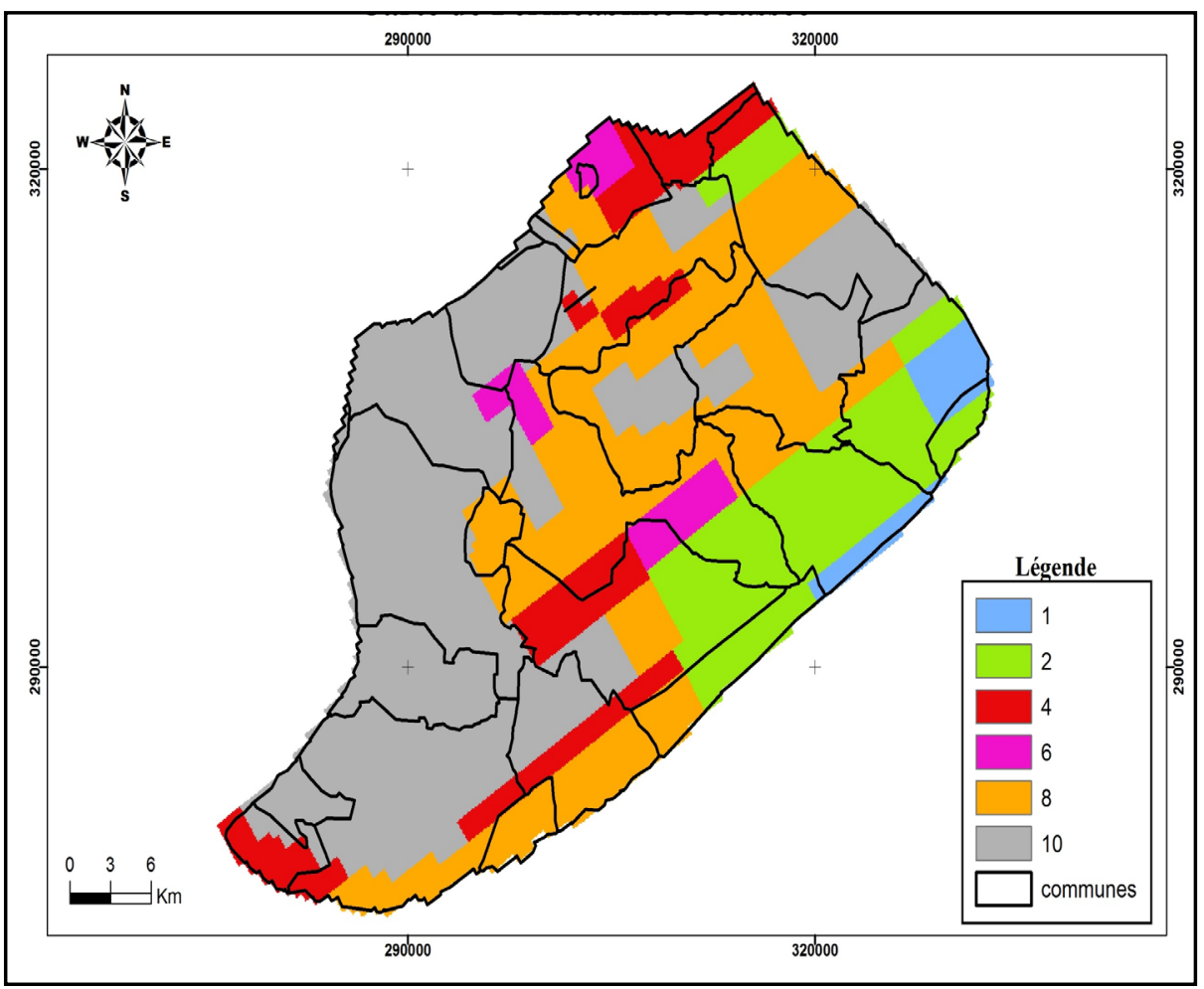

Figure 14. Map of ground water permeability after reclass.

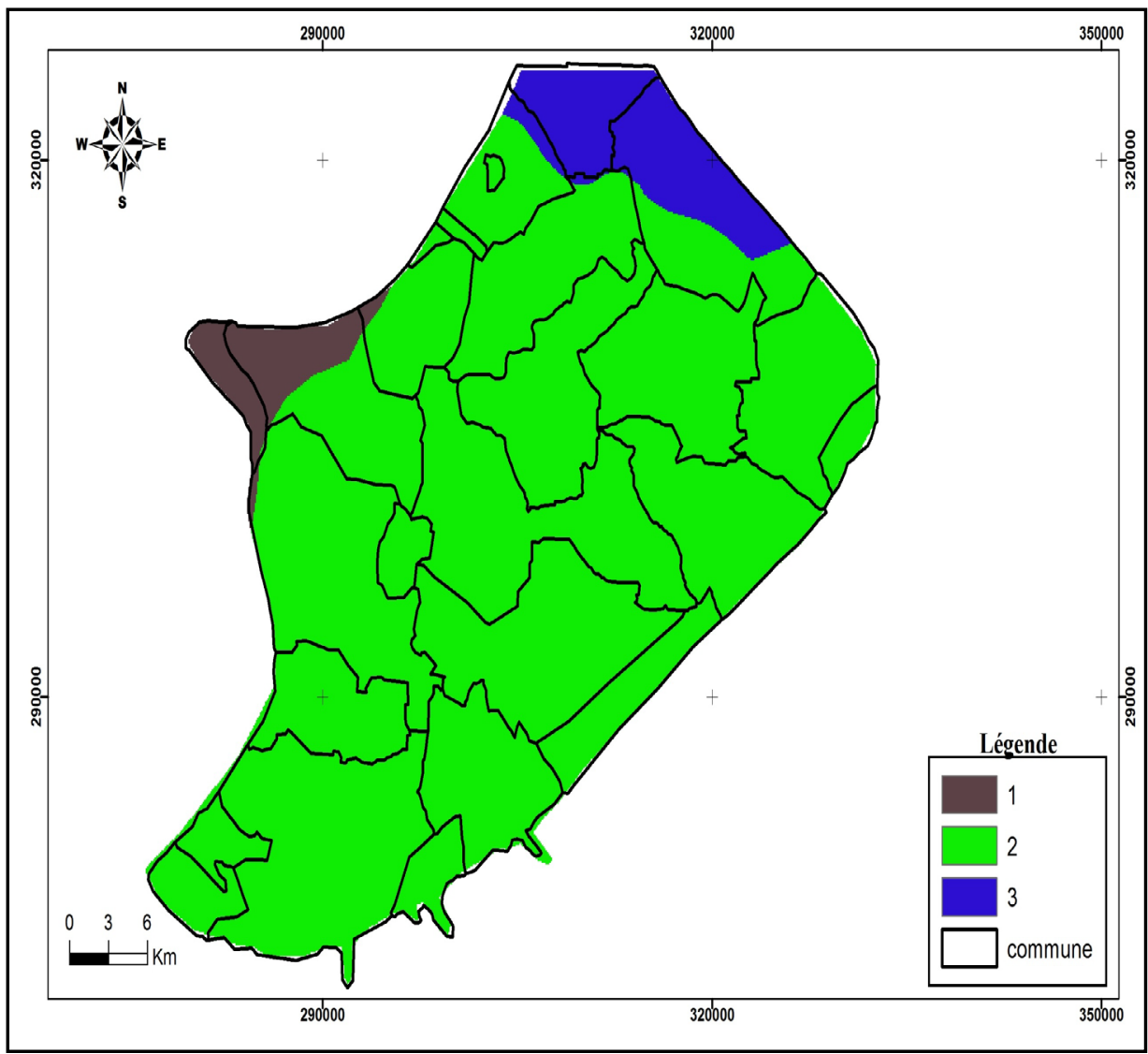

Figure 15. Map of aquifer lithology after reclass. 


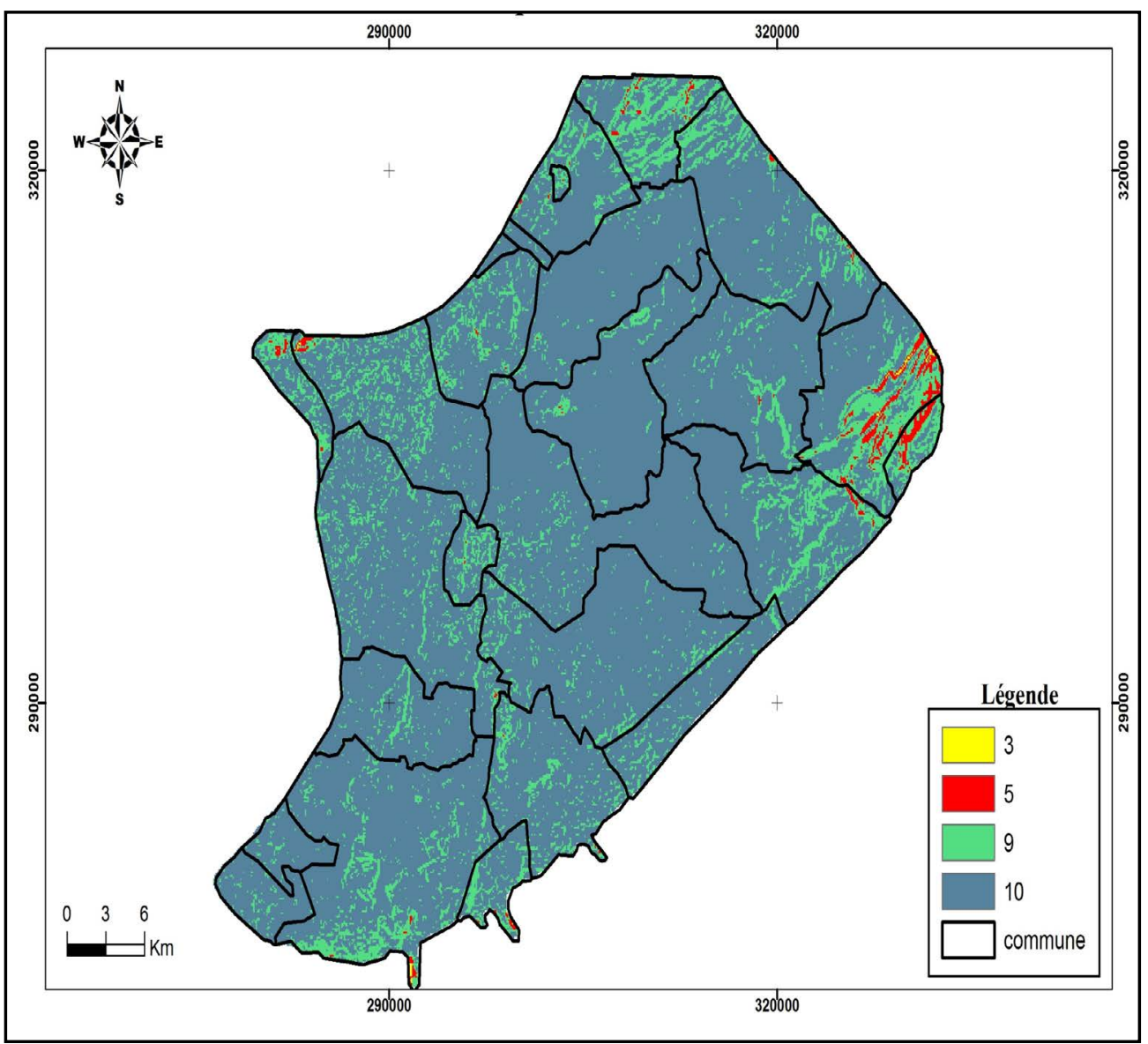

Figure 16. Map of aquifer topography after reclass.

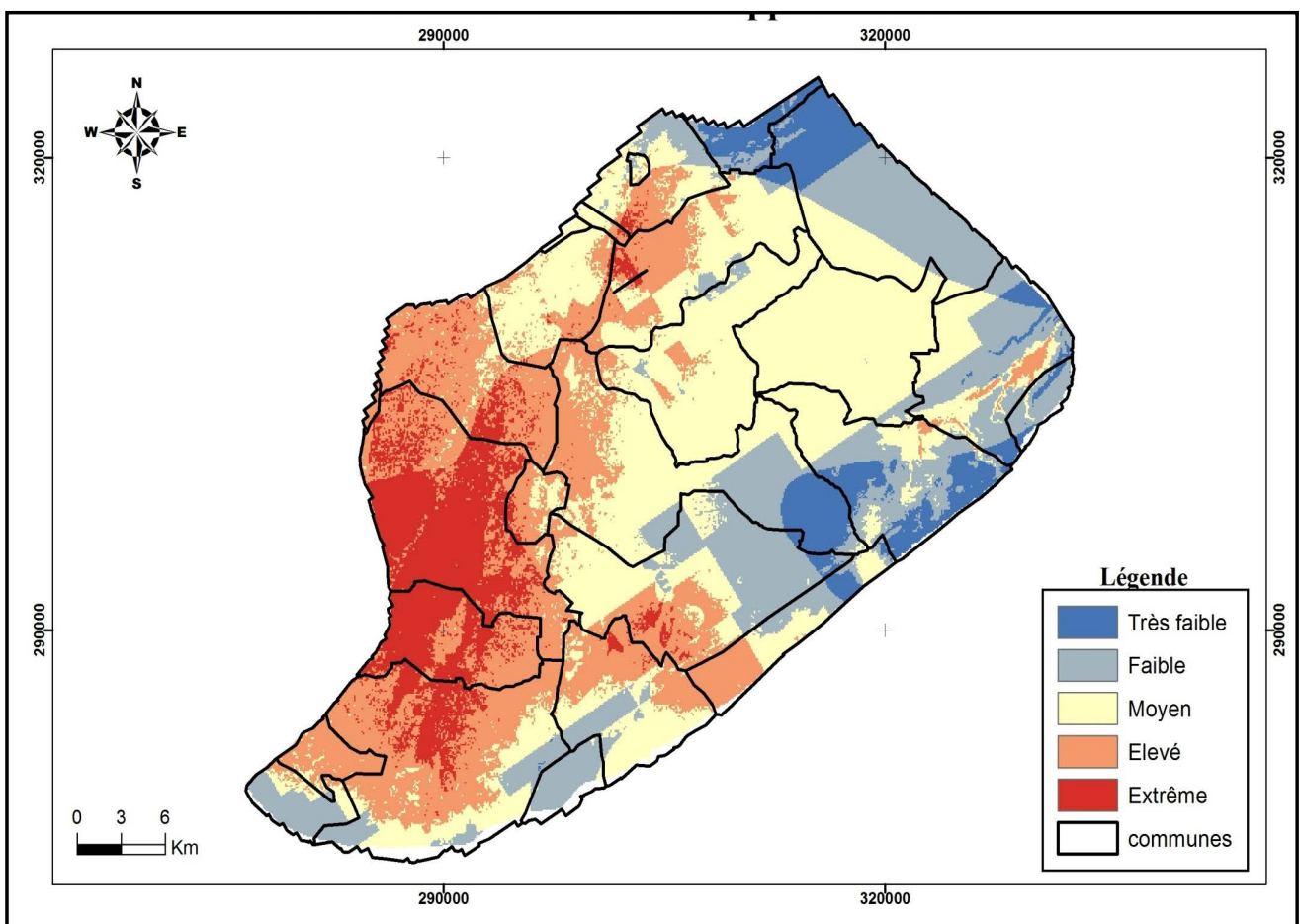

Figure 17. Map of vulnérability of Berrechid groundwater. 
The validity of the assessment of vulnerability to pollution by DRASTIC methods in the case of this study, was tested by the nitrate pollution in water. This activity was carried out by a comparison between the distribution of nitrate in ground water and the distribution of vulnerability classes.

The Validation of vulnerability maps obtained focused on the analysis of nitrate levels.

Content in groundwater in the Berrechid area.

\section{Discussion}

The analysis of the vulnerability map, determined by using the DRASTIC method allowed us to distinguish five classes of different levels of vulnerability, between 32 and 126.

These classes are mainly divided as follows:

- The first high-risk area and extreme vulnerability lies mainly in the municipalities of Berrchid, LAHSASNA, SIDI EL MEKKI and OULAD SALAH. These areas are characterized by a weak gradient of sloop ( $0 \%$ to $3 \%$, $02 \%$ ), a high aquifers permeability, shallow depth which also promotes better penetration of pollutants into the groundwater. Not to mention the impact of the unsaturated zone (UZ), which has a fine texture (silt, marl, clay) and saturated zone (SZ) (sandstone, conglomerates...) that minimizes trapping pollutant in favor of its percolation.

- The second area includes medium risk vulnerability includes common such as Kasbat BEN Mchich, OULAD Zidane and JAQMA where each parameter studied has an average value.

- The third area of low and very low risk of vulnerability that corresponds to the areas to a thickness of the relatively high unsaturated zone (HUZ), a relatively low permeability (LAMBARKIYINE, OULAD CEBBAH, Moualine EL OUAD, SIDI HAJJAJ OUAD HASSAR).

\section{Conclusions}

Overall, this study showed the wrong and improper use of ground water from the plain of Berrechid and the existence of an anthropic pollution resulting in high values of nitrates due to the discharge of solid and liquid waste from industry and domestic and also by the use of large amounts of fertilizers in agriculture.

Numerical modeling of the aquifer Berrechid allowed us to delineate the extent of groundwater pollution by nitrates and to highlight the most affected by local pollution sites.

Several phenomena contribute to the contamination of the aquifer by nitrates, namely the presence in the region of uncontrolled landfill and wastewater discharges (domestic and industrial), in addition to the use of nitrogen fertilizers.

\section{REFERENCES}

[1] L. Aller, T. Bennet, J. H. Lehr, R. J. Petty and G. Hacket, "DRASTIC: A Standardised System for Evaluating Ground Water Pollution Potential Using Hydrogeologic Settings,” EPA/600/2-87/035, Robert S. Kerr Environmental Research Laboratory, US Environmental Protection Agency, 1987.

[2] V. Murat, R. Martel, Y. Michaud and R. Therrien, "Étude Comparative des Méthodes d'Evaluationde la Vulnérabilité des Aquifères à la Pollution: Application aux Aquifères Granulaires du Piémont Laurentien, Québec,” $53 e$ Conférence Canadienne de Géotechnique, Montréal, 1518 Octobre 2000, pp. 411-418.

[3] L. Aller, T. Benett, J. H. Lehr, et al., "Drastic: A Standardized System for Evaluating Ground Water Pollution Potential Using Hydrogeologic Settings,” Rapport EPA600/2-87-035, National Water Well Association, 1987, $622 \mathrm{p}$.

[4] S. Bézèlgues, E. Des Garets, V. Mardhel and N. Dörfliger, "Cartographie de la vulnérabilité de Grand-Terre et de Marie-Galatie (Guadeloupe). Phase 1: Méthodologie de Détermination de la Vulnérabilité,” 2002, 45 p.

[5] B. A. Engel, K. C. S. Navulur, B. S. Cooper and L. Hahn, "Estimating Groundwater Vulnerability to Non-Point Source Pollution from Nitrates and Pesticides on a Regional Scale," The International Association of Hydrological Sciences, Vol. 235, No. 1, 1996, pp. 521-526.

[6] A. A. Sliman, et al., "Utilisation des Systèmes d'Information Géographique et du Model Drastique pour l'Evaluation de la Vulnérabilité des eaux Souterraines dans la Plaine de Berrchid,” Maroc Geographia Technica, No. 2, 2009, p. 83.

[7] J. P. Ruhad, “Chaouia Et Plaine De Berrechid,” In: Ressources En Eau Du Maroc. Notes et Mémoires du Service Géologique du, 1975.

[8] B. Carter, "Geographicinformation Systems for Geoscientists: Modelling with GIS," Elsevier Science Publishers, Pergamon, 1996, p. 98.

[9] D. Isabel, P. Gelinas and F. Aubre, "Cartographie de la Vulnérabilité des Eaux Souterraines au Québec,” Revue des Sciences de l'Eau, Vol. 23, No. 3, 1990, pp. 255-258.

[10] R. M. Mohamed, "Evaluation et Cartographie de la Vulnérabilité à la Pollution de l'Aquifère Alluvionnaire de la Plaine d'El Madher, Nord-Est Algérien, selon la Méthode DRASTIC,” Sciences et Changement Planétaires/Sécheresse, Vol. 12, No. 2, 2001, pp. 95-101.

[11] M. H. Hamza, A. Added, R. Rodriguez, S. Abdeljaoued and A. Ben Mammou, "A GISbased DRASTIC Vulnerability and Net Recharge Reassessment in an Aquifer of a Semiaridregion (Metline-Ras Jebel-Raf Raf Aquifer, Northern Tunisia,” Journal of Environmental Management, Vol. 84, No. 1, 2007, pp. 12-19.

[12] J. P. Jourda, K. J. Kouamé, M. G. Adja, S. K. Deh, A. T. Anani, A. T. Effini and J. Biémi, "Evaluation du Degré de Protection des Eaux Souterraines: Vulnérabilité à la Pollution de la Nappe de Bonoua (Sud-est de la Côte d'Ivoire) par la méthode DRASTIC,” Par la Méthode DRASTIC. Session Environnement/Eau, 2007,11 p. 
[13] L. Champagne and R. P.Chapuis, "Evaluation de la Vulnérabilité à la Pollution des Formations Aquifères de la MRC de Montcalm Selon la Méthode Drastic," Revue des Sciences de l'Eau, Vol. 26, No. 3, 1993, pp. 76-169.

[14] D. Sabel, P. Gelinas and F. Aubre, "Cartographie de la
Vulnérabilité des eaux Souterraines au Québec,” Revue des Sciences de l'Eau, 1990, 23 p. 